\title{
Challenging assumptions about IT skills in higher education
}

\section{Lyn Farrell}

Leeds Metropolitan University, UK

\begin{abstract}
This paper challenges the idea of 'the digital native' and the subsequent assumption of digital literacy skills amongst higher education (HE) students. It discusses the debate around the digital native theory and illustrates how, despite the growing challenges to it, the theory is still regularly used to describe student populations. It also provides a case study that demonstrates the diverse student population at Leeds Metropolitan University and the varying levels of digital literacy amongst the younger age group students. It argues that treating students as a homogenous mass is problematic and that generic technology skills do not equate to academic IT skills and that, therefore, the provision of IT support is essential for a significant portion of the HE student population.
\end{abstract}

The paper concludes with a warning that we are letting down some of our students by the Information Technology (IT) 'barrier' within higher education and that we should be focusing on identification of IT needs and IT skills acquisition support rather than assuming it is something students can 'pick up as they go along'. This will only happen once IT is given the status of a core academic skill along with maths, information literacy and academic communication.

Keywords: digital literacy; digital native; higher education; IT skills.

\section{Introduction}

The rapid rise in the use of technology has arguably changed the shape of education more than any other changes in the teaching or learning arena in recent history. Although good teaching practices and educators' expertise are the undoubted foundation of successful student experiences with education, the permeation of technology as a tool for teaching 
and learning has given rise to the need for students to acquire IT skills in order to interact fully with the education system today. It is now standard academic practice across the UK for student assignments to be word processed and most other assessed work (e.g. presentations, posters, leaflets and data sets) IT processed in some form. Access to lecture notes and supplementary teaching materials for the vast majority of departments is via an institution's virtual learning environment (VLE), which is also increasingly being used as the mode for submission of academic work. Assessment, feedback and results are increasingly being managed online. A huge number of research journals are now hosted exclusively online and the number of academic e-books has greatly increased, meaning that a huge amount of academic information today is found via the web.

\section{The digital native theory}

Alongside the growth of technology in higher education, we are educating many students who have grown up in this technological era. A great number of them will have used technologies such as the internet to download music and movies, as well as mobile phones, iPhones and iPads. Many frequently interact with a wide range of digital and online games.

Tapscott (1998) predicted over a decade ago the rise of a new generation and emphasised that they would be the very first to grow up 'surrounded by digital media'. He stated that this is a generation in touch via technology with the rest of the globe and that they learn by interacting with digital learning tools. Prensky (2001) coined the term 'digital natives' to describe 'today's students' who he says are immersed in technology and can learn about it simply by using it. He contrasted them to the 'digital immigrants' who have had to adapt to technology (some better than others) and whose learning of technology in later life, just as with language, uses a different (and by implication, inferior) part of the brain. He further claimed that this meant that technology learning for 'digital immigrants' will always be artificial, whereas for 'digital natives' it is natural, and that many 'digital immigrants' are getting left behind. He asserted that educators are now using outdated 'step by step' teaching methods because digital natives learn by exploration and experimentation. Oblinger (2003) used the term 'millennial' for students born into the 'information age' who bring with them different attitudes to education, gravitating to group 
work and exploration as a means of learning. She also stated that these students have distinct learning styles, heavy on the use of technology to aid their learning.

The digital native theorists all make claims that educators are out of step with the digital natives and that a radical change in learning via technology has occurred, which calls for radical changes in teaching methods.

\section{Assumptions about IT skills in higher education students}

The widespread acceptance of the digital native theory has given rise to the dangerous assumption that students come into higher education already equipped with academic IT skills, or that due to their immersion in social technologies, academic IT skills are something that they can 'pick up as they go along' and the question must be raised as to how much the digital native theory continues to influence such beliefs. Whenever the author presents at conferences about the need for IT provision, a large portion of the audience reports that in their institution, there is little or no formal IT support, and again, the influence of the digital native theory upon such support decisions needs investigation; we need to know how many current institutions do not offer IT support and why they feel they do not need to. There are three specific assumptions in the digital native theory that need to be challenged:

\section{Not all students are from the digital native generation}

Tapscott (1998), Prensky (2001) and Oblinger (2003) overlooked the significant portion of the higher education student population who do not fit the 'net generation' or 'digital native' category. These include mature students returning to education who previously studied before the increasing use of the internet, PC/laptop, online resources and the use of the VLE. It also includes students who work and students for whom IT at work is either specialised to the job role (e.g. nursing, building or programming) or not a core need for the role (e.g. sports). The digital native theory is not representative of the current higher education landscape and, therefore, fails at the first hurdle to adequately examine the diverse needs of a diverse student population. 


\section{Students are not a homogenous mass}

Further, Tapscott (1998), Prensky (2001) and Oblinger (2003) ignore the diversity within the 'digital' generation and treat them instead as a single homogenous mass simply due to birth date. They make assumptions largely from anecdotal evidence that is not borne out by subsequent research. There are big differences in the level of interest and engagement with IT that they have failed to address.

Bennet et al. (2008, p.779) stated that making generalisations about a generation gives rise to:

...the danger that those less interested and less able will be neglected and that the potential impact of socio-economic and cultural factors will be overlooked. It may be that there is as much variation within the digital native generation as between the generations.

Tapscott (1998) and Prensky (2001) wrote their articles at a time when there was an ongoing shift towards use of technologies. When new teaching methods are first being adopted, there is inevitably a 'switch over' period where educators and students are getting used to the change. A decade on, I believe that Prensky (2001) would find a great many 'digital immigrants' who are confident in using a range of technologies and whose interaction with technology differs little from that of the 'natives'. By focusing on this false division, he has missed the emerging differences in levels of IT skills and confidence with IT within the 'native' and 'immigrant' populations.

I believe that the evolving teaching skills of educators is a valid and valuable focus for research. Authors like Tapscott (1998), Prensky (2001) and Oblinger (2003), however, make dangerous demands about the need to overhaul teaching methods with little actual evidence of the paradigm shift in learning (via technology) that they claim.

Indeed, Margaryan and Littlejohn (2011) provided a recent and comprehensive challenge to this claim. In their survey of students studying engineering and social work they found little evidence that students learn in a significantly different way or use digital technologies in some 'radically different way'. Instead they found that both 'natives' and 'immigrants' used a similarly limited range of technology for (informal) learning that consisted mainly of 
websites and their VLE, and that both groups used social technologies. Significantly they argued that ICT skills levels vary in both student and staff populations and that this should be addressed before making sweeping changes to teaching and learning methods.

Bayne and Ross (2007) refuted the argument that current students demand more technology within teaching. Furthermore they stated that the current rush to adopt technologies without investigating the complexities of teaching practice in relation to it could be damaging. They also stated that the digital native/immigrant debate itself needed challenging as it was over-simplistic.

Oblinger (2003) asserted that the student body looks upon technology as a 'natural part of the environment'. So do I - though I am undoubtedly what Prensky (2001) calls a digital immigrant as I studied 'old school' with printed books and journals and hand written assignments. Both generalise that older generations within education can never feel truly 'natural' about the use of technology. Helsper and Eynon (2010) pointed out that most of the research to date was from studies of young people and lacked the necessary comparison with older age groups. They conducted an in-depth analysis of the 2007 Oxford Internet Survey (OxIS). They highlighted that interaction with technology (the internet in their analysis) is on a continuum of usage rather than a division between use/non-use. They found that education level and experience were far more reliable indicators of 'digital/non-digital native' status than age.

The research by Brown and Czerniewicz (2010) added to the argument that the polarisation between digital 'immigrants' and 'natives' was negative and misleading. They conducted a study spanning six years into South African students' access to and use of ICT. They found huge variation in the IT skills sets of the so-called millennial students (under 22 years): that only a quarter of those surveyed had grown up with technology and that a significant proportion had more limited experience. They also discovered that, as Helsper and Eynon (2010) predicted, a similar percentage of 'millenials' (under 25 years) and older students (26-42 years) reported ten years or more experience in using computers. Significantly they reported that 'digital native' students spanned across age groups but that all students falling into the 'digital native' category had easy access to technology outside of higher education, including private sole or primary use of a computer in a quiet space. They concluded that the digital divide stemmed from advantage/lack of opportunity with technology and not from age. 
Goode (2010) undertook a study of student access to technology at a US research university. She stated that students from poorer backgrounds usually only had public access to IT and that students attributed their expertise in IT to having access to IT at home. Those who relied on publicly available technologies lagged behind in skills levels throughout their education. Their interactions with technology in higher education actually slowed down their learning rather than enhanced it, due to their lack of knowledge of how to use it effectively.

I would argue that the reason I am confident and 'good' with IT is because I have easy access to technology. It is a fact that access to technology is unequal across society. We have a lot of students who enter university from non-traditional routes and have less experience with IT, as well as students from countries without easy access to IT. Their access to IT is via the public, rather than private, sphere and they, therefore, need extra time and space to update their existing IT skills. IT support will be needed to ensure students from all backgrounds have equal opportunity to thrive in higher education. These students will be hindered if IT skills acquisition is not built into their academic timetables.

\section{Social IT skills do not equate to academic IT skills}

Tapscott (1998), Prensky (2001) and Oblinger (2003) fail to recognise some of the specific academic IT skills that students need to study at higher education level, including advanced document formatting, analysing data, e-journal searches, creating e-portfolios, critically evaluating websites for academic use, and creating a positive online presence for employability after graduation. As Oliver and Goerke (2007, p.180) stated:

...the fact that students own devices and use social software tools for social purposes does not mean that they will necessarily transfer those behaviours to the learning context.

This is supported by the survey that Corrin et al. (2010) carried out with first year undergraduates, all born in 1980 or later. They found that students used their VLE, e-mail and the internet for academic use but that they did not integrate use of networking sites with study. Also striking is that only around half of those surveyed rated themselves as expert, opting for intermediate level instead, evidence which goes against claims of a fully digitally immersed student population. 
The two year study across five universities by Jones et al. (2010) also suggests a greater variance of IT skills in higher education students than Oblinger claimed. Jones found that the differences in use of technology (including 'Web 2.0 technologies' such as blogs, wikis and virtual worlds) varied equally within and across age groups. Furthermore, the cross over between social and educational Web 2.0 use for the 'millennial' students was surprisingly small.

Technology is dynamic and evolving and hence will continue to require support. Over ten years ago Nesi and Studman-Badillo (2000) called IT the 'fifth study skill'. They investigated the use of technology in education and reported that a large number of lecturers questioned were using IT for a range of academic purposes: their students were required to use IT to access online information such as newspapers and journals, to communicate with tutors and other students via e-mail and online discussion groups, and to format essays. They reported that the 'world wide web' was being increasingly used due to the wealth of information it housed. They also highlighted the resulting problems that students faced in identifying appropriate and accurate online information and the variance in support received to equip themselves with the requisite IT skills. They proposed that students be instructed in effective IT usage in order to minimise the pitfalls students faced. A decade on, Goode (2010, p.584) also recognised this undoubted shift towards technology in teaching and learning as 'an invisible academic prerequisite'.

However, Ferro et al. (2011) very recently highlighted that most debates on digital literacy divides still failed to focus on the different levels of interaction with digital literacy. They argued that the level of interaction will depend on the social and environmental factors driving it rather than the ability to do it; the stronger the driver, the more self-learning takes place. I have found this to be the case. Students with less experience of IT interact in a more fearful way and often comment at first that they 'won't be able to do it', despite my assurances that in my experience, as beginners progress through supportive tutorials, they learn just as quickly as other students. I always challenge their misconceptions and point out that lack of experience does not equal lack of ability, because I consistently see IT learning 'take off' when students find their confidence.

Helsper and Eynon (2010) correctly pointed out that ignoring the breadth of usage and different levels of access to technology within the supposed 'digital native' group could lead to assumptions about the presence of technology skills and cause further 
disadvantage to those most in need of additional support. There are certainly assumptions made that because students know how to use the technology in any shape or form, they know how to research, find and structure academic information effectively. Oblinger (2003) quoted a study asserting 97\% of 12-17 year olds included in the research were using the internet for school work. Usage does not, however, equate to effective use. Neither does social use of technology, such as the internet, guarantee knowledge of the specific IT tasks they need to do at university.

Littlejohn et al. (2010) acknowledged that technology tools can only have a major impact once students gain understanding of how it underpins their learning and that the assumption that social use can be transferred to the academic arena is a problematic one. It is important to remember that students' perceptions of their academic IT skills may be flawed, especially given that they are not always aware of what will be expected of them at university. Certainly Grant et al. (2009) compared students' perceptions of their IT capabilities with set IT tests consisting of commonly used tasks for university work. They tested for basic, intermediate and higher level skills and found discrepancies between perception and actual ability in Word processing and spreadsheets, although this discrepancy was not found for PowerPoint.

\section{Identify, don't assume}

Many students come to my classes in response to recommendations from their peers about the structured classes that step students through each IT task and allow them to practice what they see as they go along. Feedback consistently reports that being 'stepped through' like this helped them gain confidence in using tools and functions in Word and PowerPoint that they had not used before. This goes directly against Prensky's (2001) claims that all of today's students learn via exploration and that old classroom teaching methods are no longer viable in today's higher education climate. Rather, it supports Margaryan and Littlejohn's (2011) claims that there is no evidence of radically different learning styles in today's student population.

Littlejohn et al. (2010) and Stepankova and Engova (2006) stated students need to know how to use computers for a certain purpose. This is certainly true of the academic environment; I find that students faced with new academic tasks continue to ask for help. 
Examples include creating posters, creating online questionnaires for project surveys, analysing data with Excel tools, and creating decision 'trees' for work placement projects.

Two specific examples of current IT teaching at the author's institution, where the impact on academia comes from the increasing use of technology itself, are firstly 'evaluation of websites for use in academic work' and 'social media and employability'. The need for such classes has grown alongside the increasing use of the internet and social media like Facebook in everyday life. Prensky (2001) claimed that 'digital natives' learn by exploration, yet there has been broad failure amongst students to see the consequences of an all too public online identity in terms of employability upon graduation. Referencing of inappropriate websites as 'evidence' in academic work is also another problem in today's technology-heavy higher education. Students are failing to apply criteria for critical evaluation to internet sources and as such are citing poor quality websites as support for arguments.

Miliszewska et al. (2009) argued that in this technological age, appropriate IT skills should be embedded. They further argued that universities have a pivotal role to play in equipping graduates with the level and range of IT skills needed for their future employment. Miliszewska (2008) noted, importantly, that IT skills endured beyond graduation and pointed to universities to teach students the types of technologies key to finding employment. With graduate attributes and employability having such prominence in current higher education policy, it is important that we support students in attaining IT proficiency.

More recently Prensky (2011) has defended his terminology 'digital native/immigrant', stating that it was intended as a metaphor to describe a phenomenon rather than a literal description. He acknowledged that all people journey towards 'digital enhancement' and that the way forward now is to think of 'digital wisdom' when we consider the role and impact of technology in education. His reconsideration is timely given the newest challenges to his old position. Bennet and Maton (2011) reiterated the redundancy of treating young people as a homogenous mass and that access to technologies is not the same as use. Summarising their review of the research, they stated that young people have a commonality of usage around communication and information retrieval but other than that, there is greatly varying use of technologies. 
To summarise, the weight of evidence against the digital native theory is abundant and even Prensky has significantly changed his position in relation to it. However, it would be wrong to conclude that the theory no longer holds sway in current higher education. Bennet and Maton (2011) acknowledged that, despite the evidence contrary to the original theory's claim, 'questionable assumptions' within the theory have become widely accepted. They warned that educational institutions need to address the diverse student populations and the consequent differing levels of usage of technologies rather than let such assumptions of the 'digital native' student go unchallenged. In her keynote speech at the 2012 ALDinHE conference, Beetham repeatedly used the term 'digital native' and wrote in her address:

As older professionals we will probably never 'catch up' with students' digital knowhow...but we still have much to offer!

This strongly suggests that the original claims of 'digital native' have had a much wider impact across higher education than the later challenges to it and that we still have a long way to go to undo some of the damage done by the enduring acceptance of the theory.

\section{Skills for Learning IT sessions at Leeds Metropolitan University - a case study}

I am the academic skills tutor for IT in the Skills for Learning team at Leeds Metropolitan University. The team provides academic skills support in maths, academic communication and IT via the Skills for Learning website, drop-in workshops, tutorials, and customised teaching. Our model of academic skills support is a centrally based one, which means that we see a diverse range of students, drawn from all subject areas, across all departments and faculties, and at all levels of study, from undergraduates to PhD students. Attendance and evaluation statistics are recorded for these sessions in each academic year; an annual report on student feedback is produced to assess the service and to plan any needed changes for the following academic year. Skills for Learning has increasingly made use of technology to deliver support, including podcasts, Facebook, Twitter, screen capture, animation/quiz softwares, QR codes, and mobile technologies. Skills for Learning is, therefore, a team that embraces the potential benefits of technologies for teaching and learning. 
However, in over eight years of teaching IT to students, the author's own experience of student IT skills is at odds with the assumptions of the digital native theorists. A calculation of the attendance figures for IT classes, combined with traffic at the IT helpdesk, as a percentage of the approximate total student population is around fifty nine percent. (This is a rather imprecise calculation. It can't determine people attending multiple classes or asking multiple queries. However, it gives a glimpse into the number of basic IT support queries over the past academic year). The numbers of students voluntarily attending IT drop-in workshops has increased significantly year on year, as shown in Chart 1.

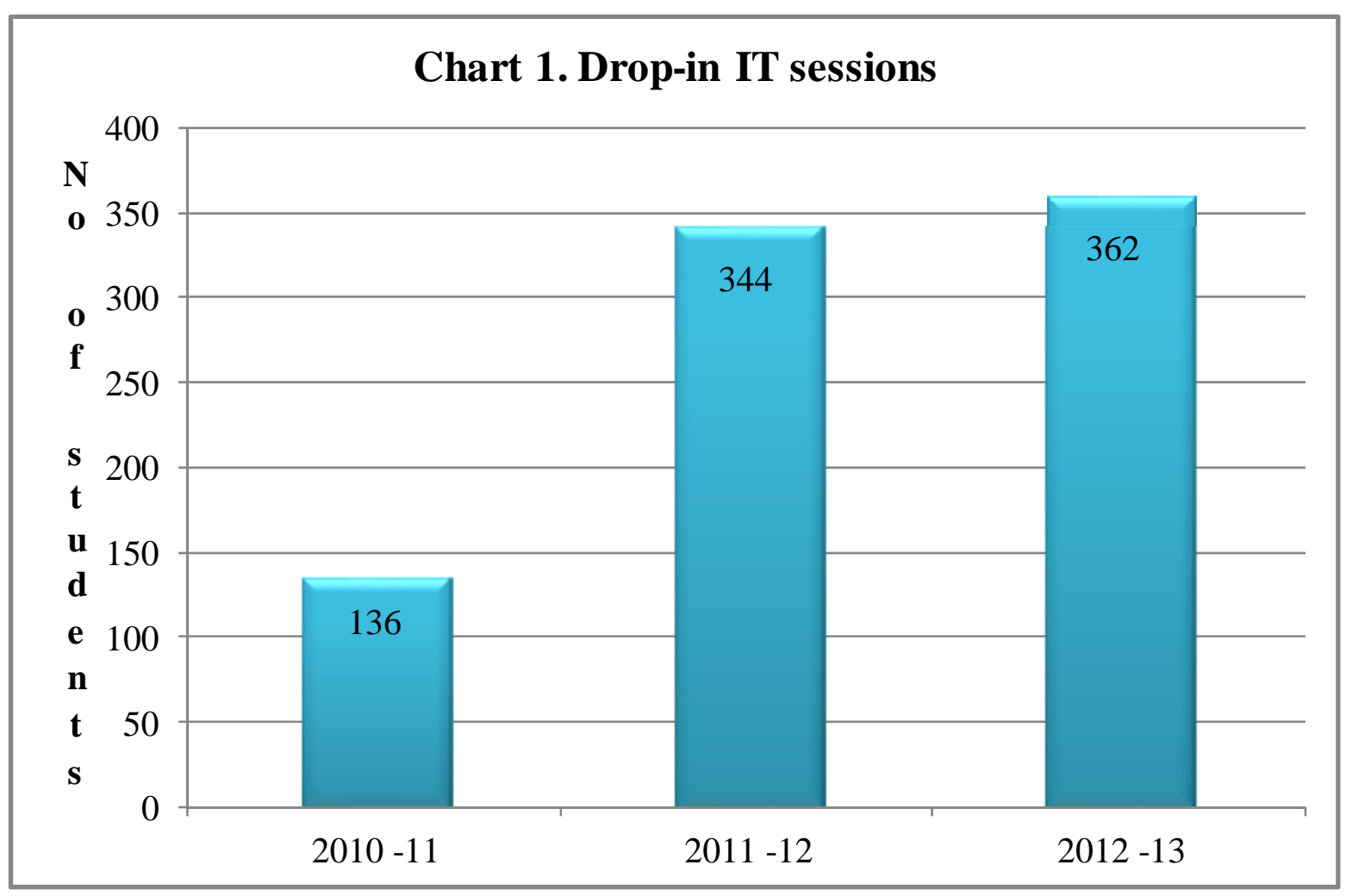

A large number of students every year need support to some level in Word, PowerPoint and Excel. In the past academic year, many tutorials were given on beginner topics including Microsoft Office, file management, uploading and downloading files, navigating through the VLE, using e-mail and adding e-mail attachments, and offer several 'beyond the basics' Office classes also. New drop-in classes are added each academic year in response to requests from colleagues or students. From Autumn 2012, for example, 'Online identity and employability' and 'Introduction to Pebblepad e-portfolio' were newly introduced. The full list of classes currently on offer is shown in Table 1. 
Table 1. Full list of class and tutorial topics from Autumn 2012

\begin{tabular}{|l|l|}
\hline Logging in at Leeds Met & Posters with PowerPoint \\
\hline Introduction to Google e-mail & Introduction to Excel \\
\hline Introduction to IT & Excel - beyond the basics \\
\hline Saving and storing computer files & Excel formula \\
\hline Introduction to Word & Excel Pivot tables \\
\hline Word - beyond the basics & Mind mapping with Inspiration software \\
\hline Word for dissertations and reports & Online identity and employability \\
\hline Images and tables in Word and PowerPoint & Introduction to Pebblepad e-portfolios \\
\hline Presentations with PowerPoint & Introduction to Publisher \\
\hline
\end{tabular}

Firstly, given the widespread belief in digital native students, a surprising number of students who present themselves for support (via drop-in classes or tutorials) are from the younger age groups. Our records of attendance for drop-in classes show that a clear majority of students (over 70\%) are from the 21-30 age group (we do not collect feedback after tutorials as many tutorials are one-to-one and asking for feedback in this setting would not allow for confidentiality of that feedback).

The significant growth of support has been in customised sessions. Academic colleagues are increasingly reporting that their students lack academic IT skills for tasks they need to do as part of their course. Recent examples include Word for dissertations or reports, Excel for analysing sports data, PowerPoint for creating e-posters, and Inspiration for creating decision trees. As a result, they refer students from whole cohorts to us for 'customised' sessions. The increase in attendance is in a large part due to these customised sessions. A full list of the classes taught in response to requests from academic colleagues is shown in Table 2 (note: some overlap with drop-in classes). 


\section{Table 2. Full list of customised classes taught}

\begin{tabular}{|ll|}
\hline Introduction to Excel & Presentations with PowerPoint \\
\hline Creating charts in Excel & Drawing objects in PowerPoint \\
\hline $\begin{array}{l}\text { Introductory Excel for sports } \\
\text { physiology }\end{array}$ & Posters with PowerPoint \\
\hline Film Budgets with Excel & Recording narration onto PowerPoint \\
\hline Introduction to Word & PowerPoint slide master \\
\hline Word beyond the basics & Mind mapping with Inspiration software \\
\hline Word for dissertations and reports & Decision trees with Inspiration software \\
\hline
\end{tabular}

In customised sessions, students often rate themselves as already understanding how to use particular software. However, after the session, the variation in skills amongst all ages of students is apparent. They often state that they 'did not realise there were so many tips on working faster and avoiding formatting errors'. They commonly make basic level errors including using the space bar instead of tabs, using the enter key instead of control and enter for new pages. They also often do not know about paragraph formatting, and find keyboard shortcuts and function keys useful. Approximately 40 percent of students seen were not aware of section breaks, advanced page numbering, heading styles, creating Excel tables, using functions and formula, creating graphical effects from Smart Art among others. A great many still create a manual table of contents for dissertations and theses instead of using Word's automated tools.

Secondly, if the digital native theory was true, demand for classes would surely diminish year on year. Instead, the opposite is true - students from the younger age groups continue to drop in or be referred to IT classes. As charts 1, 2 and 4 illustrate, the number of sessions have risen year on year since the project started. This is true for drop-in classes and customised classes. Tutorials have gone down from last year but there are several possible reasons for this. Firstly, as students find support through the provision of customised teaching, the need for tutorial help might have diminished. Secondly, the rise in teaching hours given to customised sessions has led to limits being set on one-to-one tutorials. Students have been directed towards drop in workshops, or where demand was high enough, ad hoc group tutorial sessions arranged with academic colleagues. 

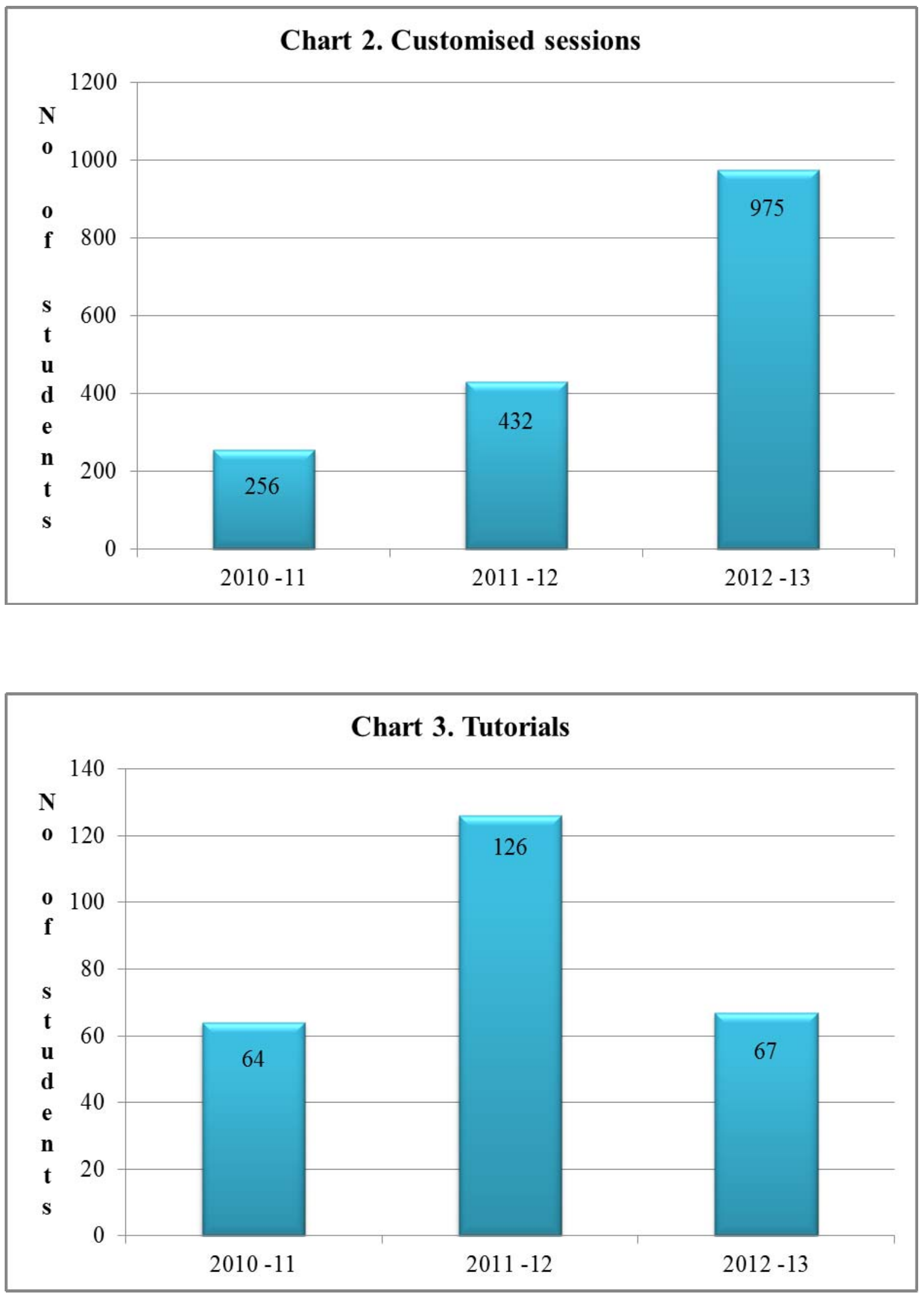


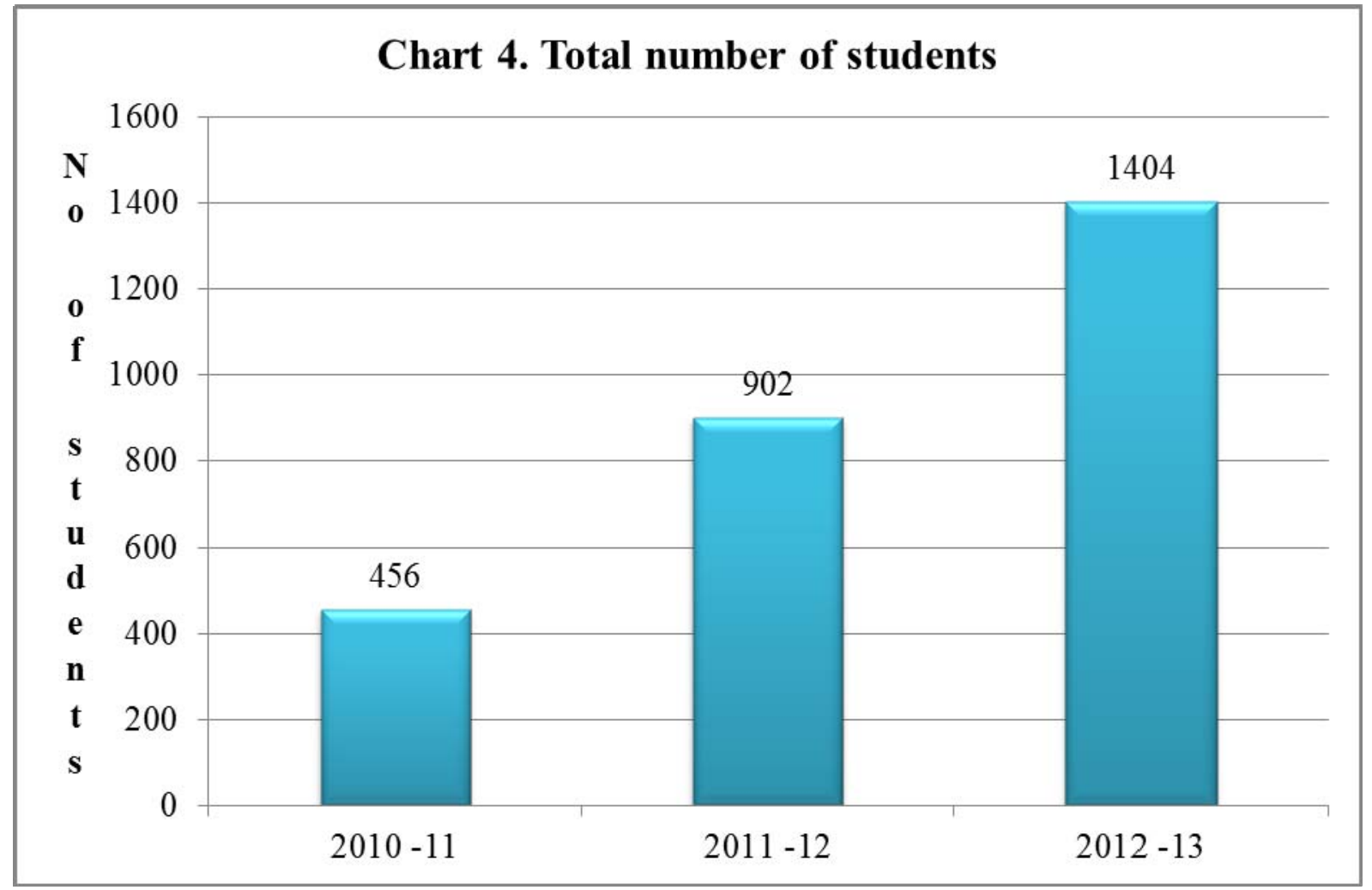

Leeds Metropolitan University also employs a team of IT help assistants who staff the IT counter of the Help and Information Point in the library from 8am to 6pm, Monday to Saturday in term time. They deal with an average of fifty IT queries per day at each campus, over two thousand queries on average per month, amounting to sixteen thousand queries on average per academic year. It was reported that a significant number of younger students who, just as with the wider student population, need varying levels of help with IT.

One assistant reported that it is not a matter of age but of previous interaction with the computer. As it can be observed from the list of questions dealt with in Table 3, many students display gaps in their IT knowledge at a basic level. 
Table 3. Common questions at the IT Helpdesk

\begin{tabular}{|ll|}
\hline Individual page pagination & Printing and scanning \\
\hline Section breaks & Resetting passwords \\
\hline Table of contents & Wireless setup/use of \\
\hline Headings and other styles & File locations \\
\hline Advanced numbering & File suffixes \\
\hline Excel basics & What 'Drive' letters mean \\
\hline $\begin{array}{l}\text { Insert text boxes/shapes Charts/graphs and } \\
\text { data series }\end{array}$ & Using Google E-mail \\
\hline Inserting images/text & \\
\hline Shape/image effects & E-mail attachments \\
\hline Animations & Saving and downloading \\
\hline
\end{tabular}

Finally, despite the efforts of the Skills for Learning team to inform new students about available services during induction weeks, every year there are students who only find out about the service half way through the year or later. It is beyond the remit of this paper to consider the reasons for this in detail (for example induction 'overload' or academic staff who do not pass on information to their students) but it should be noted as the context in which teaching takes place.

The growth in the number of classes year on year and the consistent requests for help with IT tasks from basic to more advanced levels and, significantly, across the age groups, clearly indicates that students need IT support.

\section{Conclusion}

The belief in the 'digital native' student population has increasingly been challenged within research. Despite such challenges from those that disagree, it has persevered in academic discourse and this has surely had some impact both on service provision and the student experience. In both student and staff bodies there is a mix of technology enthusiasts, technology users and technology novices. Interaction or lack of interaction with technology has more to do with opportunity or interest than age. 
In direct negation of the belief by many that students will be teaching the educators in terms of technologies, the student population remains far more complex and diverse than such a position allows for. In my own experience as a university IT tutor over the past eight years, the need for IT support for a significant number of students remains very apparent.

A comprehensive picture of IT skills in current UK higher education students is lacking in current research. A survey of current UK student populations and their access to and use of IT, similar to that in South Africa by Brown and Czerniewicz (2010), and building on the research of Margaryan and Littlejohn (2011), is therefore crucial.

I strongly believe such research would echo the results of the case study; that the UK student population is diverse with a huge variation in IT skills. An evaluation of the impact of playing 'catch up' with IT skills acquisition in students coming into higher education is also essential. If the experiences of this institution's students are reflected across the UK, there are a substantial number of higher education students having to struggle daily with IT systems without structured support. 'Picking it up as you go along' has been at the great cost of personal academic study time for many students.

Rather than assuming IT knowledge in today's student populations and upholding misleading notions of native/immigrant, we need to focus on effective identification of different skills levels and sufficient support in higher education. This is done at most UK universities for academic communication, maths, statistics and information literacy, yet we neglect IT skills in a way that creates barriers to learning and will undoubtedly impact upon student retention. IT skills support has to be recognised as an integral part of academic success, not only because it is crucial to students who would otherwise struggle with IT throughout their academic studies, but because there are gaps in students' IT knowledge which impacts on IT processed work. This can only happen when IT is awarded the status of academic skill, with IT skills development embedded within all higher education courses. 


\section{References}

Bayne, S. and Ross, J. (2007) 'The 'digital native' and 'digital immigrant': a dangerous opposition', Annual Conference of the Society for Research into Higher Education (SRHE) Brighton, Sussex 11-13 December [Online]. Available at: http://www.academia.edu (Accessed: 22 August 2012).

Beetham, H. (2012) 'Strange encounters: academic learning and digital know-how', Proceedings of the ALDinHE Conference. Leeds 2-4 April [Online]. Available at: http://www.aldinhe.ac.uk/leeds12.htm (Accessed: 10 October 2013).

Bennett, S., Maton, K. and Kervin, L. (2008) 'The'digital natives' debate: a critical review of the evidence', British Journal of Educational Technology, 39(5), pp. 775-786.

Bennet, S. and Maton, K. (2011) 'Intellectual field or faith based religion: moving on from the idea of digital natives', in Thomas, M. (ed.) Deconstructing digital natives. New York and London: Routledge, pp. 169-185.

Brown, C. and Czerniewicz, L. (2010) 'Debunking the 'digital native': beyond digital apartheid, towards digital democracy', Journal of Computer Assisted Learning, 26(5), pp. 357-369.

Corrin, L., Bennett, S. and Lockyer, L. (2010) 'Digital natives: everyday life versus academic study', Proceedings of the 7th International Conference on Networked Learning 2010. Denmark 3-4 May [Online]. Available at: http://www.lancaster.ac.uk/fss/organisations/netlc/past/nlc2010/index.htm (Accessed: 22 October 2012).

Ferro, E., Helbig, N. and Gil-Garcia, R. (2011) 'The role of IT literacy in defining digital divide policy needs', Government Information Quarterly, 28(1), pp. 3-10.

Grant, M., Malloy, A. and Murphy, M. (2009) 'A comparison of student perceptions of their computer skills to their actual abilities', Journal of Information Technology Education, 8, pp. 141-160. 
Goode, J. (2010) 'Mind the gap: The digital dimension of college access', The Journal of Higher Education, 8(5), pp. 582-617.

Helsper, E. and Eynon, R. (2010) 'Digital natives: where is the evidence?', British Educational Research Journal, 36 (3), pp. 503-520.

Jones, C., Ramanau, R., Cross, S. and Healing, G. (2010) 'Net generation or digital natives: is there a distinct new generation entering university?', Computers and Education, 54(3), pp. 722-732 [Online]. Available at: http://www.journals.elsevier.com/computers-and-education/ (Accessed: 12 December 2012).

Littlejohn, A., Margaryan, A. and Vojt, G. (2010) ‘Exploring students’ use of ICT and expectations of learning methods', Electronic Journal of e-Learning, 8(1), pp.13-20 [Online]. Available at: www.ejel.org (Accessed: 10 January 2013).

Margaryan, A. and Littlejohn, A. (2011) 'Are digital natives a myth or reality?: Students' use of technologies for learning', Computers \& Education, 56(2), pp. 429-440.

Miliszewska, I. (2008) 'ICT skills: an essential graduate skill in today's global economy?', Proceedings of the Informing Science \& IT Education Conference (InSITE) 2008. Bulgaria 22-25 June [Online]. Available at: http://proceedings.informingscience.org/ (Accessed: 16 August 2012).

Miliszewska, I., Venables, A. and Tan, G. (2009) 'How generic is I(nformation) T(echnology)?', Issues in Informing Science and Information Technology, 6, pp. 193-199 [Online]. Available at: http://www.informingscience.us/icarus/journals/iisit/ (Accessed: 24 August 2012).

Nesi, H. and Studman-Badillo, B. (2000) 'The fifth study skill: assumptions and expectations regarding the role of the Internet in British universities', in Howarth, P. and Herington, R. (eds.) EAP learning technologies. Leeds: Leeds University Press, pp. 1-8. 
Oblinger, D. (2003) 'Boomers, gen-xers and millennials: understanding the new students', EDUCAUSE Review, 38(4), pp. 37-47 [Online]. Available at: http://www.educause.edu/ (Accessed: 5 August 2012).

Oliver, B. and Goerke, V. (2007) 'Australian undergraduates' use and ownership of emerging technologies: implications and opportunities for creating engaging learning experiences for the Net generation', Australasian Journal of Educational Technology, 23(2), pp. 171-186 [Online]. Available at: http://www.ascilite.org.au/ (Accessed: 22 August 2012).

Prensky, M. (2001) 'Digital natives, digital immigrants', On the Horizon, 9(5), pp. 1-6 [Online]. Available at: http://marcprensky.com/ (Accessed: 5 August 2012).

Prensky, M. (2011) 'Digital wisdom and homo sapiens digital', in Thomas, M. (ed.) Deconstructing digital natives. New York and London: Routledge, pp. 15-29.

Štepánková, O. and Engová, D. (2006) ‘Professional competence and computer literacy in e-age: focus on healthcare', Methods of Information in Medicine, 45(3), pp. 300-304 [Online]. Available at: http://www.schattauer.de/en/magazine/subject-areas/journalsa-z/methods.html (Accessed: 12 March 2013).

Tapscott, D. (1998) Growing up digital: the rise of the Net generation. New York: McGrawHill.

\section{Author details}

Lyn Farrell is an academic skills tutor (IT) at Leeds Metropolitan University. Her research interests are in students' IT skills in current higher education, the perpetuation of the digital native myth, IT toolkits for academic skills, social media and online identity and technology and education. 